Article

\title{
Heterogeneously Integrated Distributed Feedback Quantum Cascade Lasers on Silicon
}

\author{
Alexander Spott ${ }^{1}$ * , Jon Peters ${ }^{1}$, Michael L. Davenport ${ }^{1}$, Eric J. Stanton ${ }^{1}$, Chong Zhang ${ }^{1}$, \\ Charles D. Merritt ${ }^{2}$, William W. Bewley ${ }^{2}$, Igor Vurgaftman ${ }^{2}$, Chul Soo Kim ${ }^{2}$, Jerry R. Meyer ${ }^{2}$, \\ Jeremy Kirch $^{3}$, Luke J. Mawst ${ }^{3}$, Dan Botez ${ }^{3}$ and John E. Bowers ${ }^{1}$ \\ 1 Department of Electrical and Computer Engineering, University of California, Santa Barbara, CA 93106, \\ USA; peters@ece.ucsb.edu (J.P.); mld01@umail.ucsb.edu (M.L.D.); estanton@ece.ucsb.edu (E.J.S.); \\ czhang@ece.ucsb.edu (C.Z.); bowers@ece.ucsb.edu (J.E.B.) \\ 2 Code 5613, Naval Research Laboratory, Washington, DC 20375, USA; charles.merritt@nrl.navy.mil (C.D.M.); \\ william.bewley@nrl.navy.mil (W.W.B.); igor.vurgaftman@nrl.navy.mil (I.V.); \\ chulsoo.kim@nrl.navy.mil (C.S.K.); jerry.meyer@nrl.navy.mil (J.R.M.) \\ 3 Department of Electrical and Computer Engineering, University of Wisconsin, Madison, WI 53706, USA; \\ jdkirch@wisc.edu (J.K.); mawst@engr.wisc.edu (L.J.M.); botez@engr.wisc.edu (D.B.) \\ * Correspondence: spott@ece.ucsb.edu; Tel.: +1-206-659-7363
}

Received: 28 April 2016; Accepted: 30 May 2016; Published: 2 June 2016

\begin{abstract}
Silicon integration of mid-infrared (MIR) photonic devices promises to enable low-cost, compact sensing and detection capabilities that are compatible with existing silicon photonic and silicon electronic technologies. Heterogeneous integration by bonding III-V wafers to silicon waveguides has been employed previously to build integrated diode lasers for wavelengths from 1310 to 2010 nm. Recently, Fabry-Pérot Quantum Cascade Lasers integrated on silicon provided a $4800 \mathrm{~nm}$ light source for mid-infrared (MIR) silicon photonic applications. Distributed feedback (DFB) lasers are appealing for many high-sensitivity chemical spectroscopic sensing applications that require a single frequency, narrow-linewidth MIR source. While heterogeneously integrated $1550 \mathrm{~nm}$ DFB lasers have been demonstrated by introducing a shallow surface grating on a silicon waveguide within the active region, no mid-infrared DFB laser on silicon has been reported to date. Here we demonstrate quantum cascade DFB lasers heterogeneously integrated with silicon-on-nitride-on-insulator (SONOI) waveguides. These lasers emit over $200 \mathrm{~mW}$ of pulsed power at room temperature and operate up to $100{ }^{\circ} \mathrm{C}$. Although the output is not single mode, the DFB grating nonetheless imposes wavelength selectivity with $22 \mathrm{~nm}$ of thermal tuning.
\end{abstract}

Keywords: quantum cascade laser; silicon photonics; distributed feedback laser; mid-infrared

\section{Introduction}

Mid-infrared (MIR) silicon photonic integration offers the opportunity to build inexpensive, compact devices or systems that address a variety of sensing and detection applications on silicon chips. Scientific, medical, industrial, and military technologies using MIR wavelengths can potentially be addressed with applications in spectroscopic analysis [1], biological sensing [2], environmental monitoring [3], and astronomy [4]. While a number of passive MIR photonic waveguides and devices have been constructed on a variety of silicon waveguide platforms [5-8], the development of integrated active components on silicon for longer wavelengths has been more limited. Thermo-optic phase shifters for the $5 \mu \mathrm{m}$ range [9], heterogeneously integrated InP-based type-II photodiodes for wavelengths up to $2.4 \mu \mathrm{m}$ [10], demultiplexers for the $2 \mu \mathrm{m}$ range utilizing an array of similar photodiodes [11], a fully integrated spectrometer utilizing an array of $\operatorname{InAs}_{0.91} \mathrm{Sb}_{0.09}$-based photodiodes for 3-4 $\mu \mathrm{m}$ [12], and multiple-quantum-well InGaAs lasers which emit $2.01 \mu \mathrm{m}$ light in continuous wave $(\mathrm{CW})$ mode at room temperature [13] have been reported. 
Although InP-based diode lasers become impractical at wavelengths beyond $\sim 2.4 \mu \mathrm{m}$, the quantum cascade laser (QCL) [14] and interband cascade laser (ICL) $[15,16]$ technologies provide a promising basis for integrated coherent sources extending throughout the MIR and longwave IR (LWIR) spectral bands. As a first step toward this objective, we recently reported the first successful demonstration of QCLs on silicon [17]. These Fabry-Pérot lasers emitted at $4.8 \mu \mathrm{m}$ when operated in pulsed mode at room temperature, with peak output powers up to $31 \mathrm{~mW}$ when tapers were used to transfer light from the hybrid $\mathrm{Si} / \mathrm{III}-\mathrm{V}$ active gain region into passive silicon waveguides.

Both the QCLs from [17] and the devices discussed here were integrated on the silicon-on-nitride-on-insulator (SONOI) waveguide platform, which consists of silicon waveguides above a thin $\mathrm{Si}_{3} \mathrm{~N}_{4}$ cladding, a thick $\mathrm{SiO}_{2}$ cladding, and a silicon substrate. This $\mathrm{SONOI}$ waveguide can support wavelengths from $1.2 \mu \mathrm{m}$ to $6.7 \mu \mathrm{m}$. Additionally, by etching off the top silicon waveguide layer, nitride-on-insulator waveguides can be constructed for propagation at $350 \mathrm{~nm}$ to $3.5 \mu \mathrm{m}$. Thus, by employing both of these options in different regions, a single silicon photonic chip can be constructed that supports all wavelengths from $350 \mathrm{~nm}$ to $6.7 \mu \mathrm{m}$.

Wavelength-selective feedback mechanisms such as gratings or loop mirrors, which we have demonstrated at shorter wavelengths [18], may also be adapted to MIR QCLs on silicon. Distributed-feedback (DFB) lasers are attractive in many sensing applications, such as laser-based chemical bond spectroscopy, gas analysis [19], and explosive detection [20], which require a single frequency, narrow-linewidth source. Typically, gratings for QCLs are defined on the laser ridge sidewalls [21], as a surface grating on the top of the laser [22], or buried within a cladding layer [23]. Heterogeneous integration offers the additional option of etching a shallow surface grating into the silicon waveguide underneath the III-V mesa [24], to provide distributed feedback without the need for epitaxial regrowth. In the present work, we have demonstrated DFB QCLs integrated with SONOI waveguides on a silicon substrate, although single-mode operation has not been obtained. These lasers output over $200 \mathrm{~mW}$ of peak power from a hybrid Si/III-V facet, and operate to $100{ }^{\circ} \mathrm{C}$.

\section{Fabrication and Design}

The integrated laser structure, SONOI waveguide platform, and fabrication process are described in [17]. Figure 1a shows a three-dimensional (3D) illustration of the SONOI waveguide with an etched surface grating underlying the III-V layers and Figure $1 \mathrm{~b}$ illustrates the DFB QCL, which consists of a hybrid $\mathrm{Si} / \mathrm{III}-\mathrm{V}$ active region coupled by III-V tapers to passive silicon waveguides on both sides. End facets are formed by mechanically polishing the passive SONOI waveguides. The 3-mm-long active region is positioned on top of a quarter-wavelength-shifted shallow DFB surface grating that extends throughout the underlying silicon waveguide. The SONOI waveguide is fully etched and $1.5 \mu \mathrm{m}$ tall.

(a)

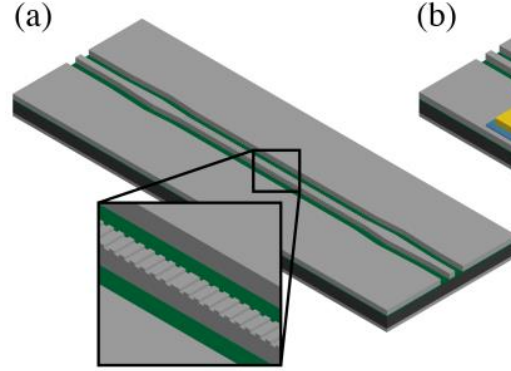

(c)

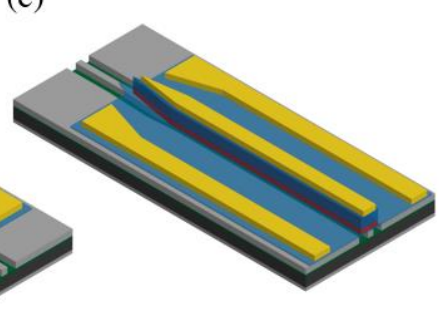

Figure 1. A 3D schematic of: (a) a SONOI waveguide with shallow surface DFB grating, which lies underneath the integrated QCL; (b) a DFB QCL heterogeneously integrated with a SONOI waveguide, including III-V tapers on both sides of the laser designed to transfer light from the hybrid Si/III-V active region to passive SONOI waveguides; (c) an integrated DFB QCL with one taper removed to expose a polished hybrid $\mathrm{Si} / \mathrm{III}-\mathrm{V}$ facet. 
Before the silicon waveguide is etched, the grating is patterned onto the silicon with electron beam lithography (EBL) and formed with a $\mathrm{C}_{4} \mathrm{~F}_{8} / \mathrm{SF}_{6} / \mathrm{Ar}$ inductively coupled plasma (ICP) etch. The grating period employed for different devices on the chip ranges from 738 to $778 \mathrm{~nm}$. Atomic force microscope (AFM) measurements of one device found a $\sim 31 \%$ etched silicon duty cycle and $28 \mathrm{~nm}$ etch depth.

The silicon waveguides in the passive regions and output facets are $2 \mu \mathrm{m}$ wide. However, the silicon waveguides expand underneath the III-V taper to aid the mode conversion. For subsequent measurements carried out to clarify the role of the tapers in the laser operation, the tapers adjacent to the output facet were removed by polishing back to immediately past the tapers. In that case, the silicon waveguide at the resulting hybrid Si/III-V output facet was slightly wider than within the rest of the hybrid active region. Figure $1 \mathrm{c}$ depicts the laser structure with one taper removed.

The QCL material with 30 stages was grown by metalorganic chemical vapor deposition (MOCVD) at U. Wisconsin, Madison. The design was similar to that shown in [25] and modified for flip-chip bonding for heterogeneous integration. In particular, a thin bottom InP contact layer and thick top InP cladding were used to increase optical confinement in the silicon waveguide while preventing overlap with the top metal.

Four laser configurations with different active region waveguide geometries were tested. Figure 2 shows active region cross-sections for the four designs labeled A-D. Designs A-C contain fully etched narrow III-V ridges as in [17], with mesa widths of $4 \mu \mathrm{m}, 6 \mu \mathrm{m}$ and $8 \mu \mathrm{m}$, respectively. Design D alternatively has a $6-\mu \mathrm{m}$-wide upper cladding combined with a $24-\mu \mathrm{m}$-wide active region. The width of the silicon waveguide underneath the active region is $1.5 \mu \mathrm{m}$ for Designs $\mathrm{A}, \mathrm{B}$, and D and $3.5 \mu \mathrm{m}$ for Design C. Figure 2 also overlays simulated optical modes onto the four waveguide cross-sections, along with estimated transverse optical confinement factors $(\Gamma)$ in the active QCL stages. Both the active region confinement and optical overlap with the gratings etched into the underlying silicon depend on the widths of the III-V and silicon waveguides. Single-mode operation requires careful design of the laser geometry, so as to optimize both the net modal gain and the guided-mode mirror reflectivity. Fortunately, the heterogeneous silicon platform provides enhanced engineering versatility. For example, Design D, with its narrow silicon waveguide and wide active region, reduces the optical loss induced by sidewall roughness, while potentially maintaining operation in a single lateral mode. Since the current spreading below the lasing threshold is significant in QCLs, this is achieved at the expense of increasing the threshold current by the ratio of the active region width to the lateral modal extent. The far-field profiles discussed in the Results Section appear to show that, in agreement with the mode simulations illustrated in Figure 2, Designs A, B, and D lase primarily in the $\mathrm{TM}_{00}$ mode while Design $C$ lases primarily in the higher-order $\mathrm{TM}_{10}$ mode.

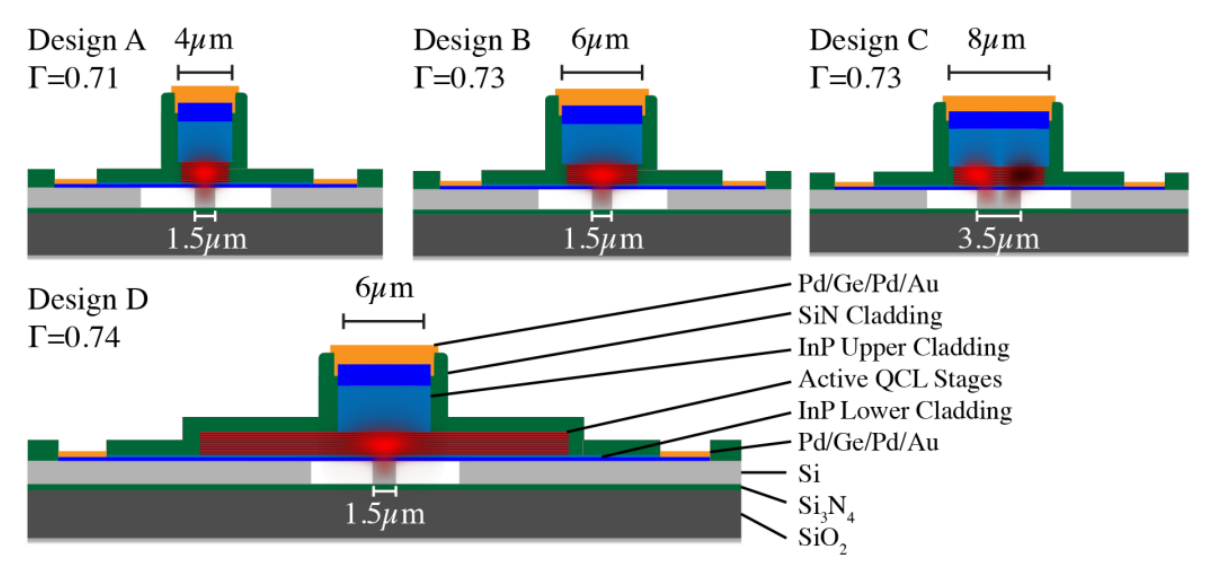

Figure 2. Cross-sectional schematics of the active regions for four different DFB QCL designs. Simulated optical modes are overlaid $\left(\mathrm{TM}_{00}\right.$ for Designs $\mathrm{A}, \mathrm{B}$, and $\mathrm{D}$, and $\mathrm{TM}_{10}$ for Design $\mathrm{C}$ ), and the active region transverse optical confinement factor $\Gamma$ for each design is indicated. 


\section{Results}

The DFB QCLs were driven with 250 -ns-wide pulses at a $1 \mathrm{kHz}$ repetition rate. The $L-I-V$ characteristics at $20^{\circ} \mathrm{C}$ of each device were measured both before and after removal of the III-V tapers. Figure 3 shows the best of the results for a device (of Design D) before the taper was removed (with the assumption that the current spreads uniformly over the $24-\mu \mathrm{m}$-wide active region). Although the threshold current density appears quite low $\left(0.58 \mathrm{kA} / \mathrm{cm}^{2}\right)$, the maximum output power is only $11 \mathrm{~mW}$, and the differential slope efficiency is only $23 \mathrm{~mW} / \mathrm{A}$. These observations would be inconsistent if obtained for a conventional QCL geometry with cleaved facets, since the observed low efficiency implies a high loss, which should greatly increase the threshold current density. Other devices of all four designs also displayed relatively low threshold current densities of $0.6-1.2 \mathrm{kA} / \mathrm{cm}^{2}$, but even lower maximum output powers of 1.2-4.1 mW. Several of the devices (of Designs B and C) did not produce enough light to measure.

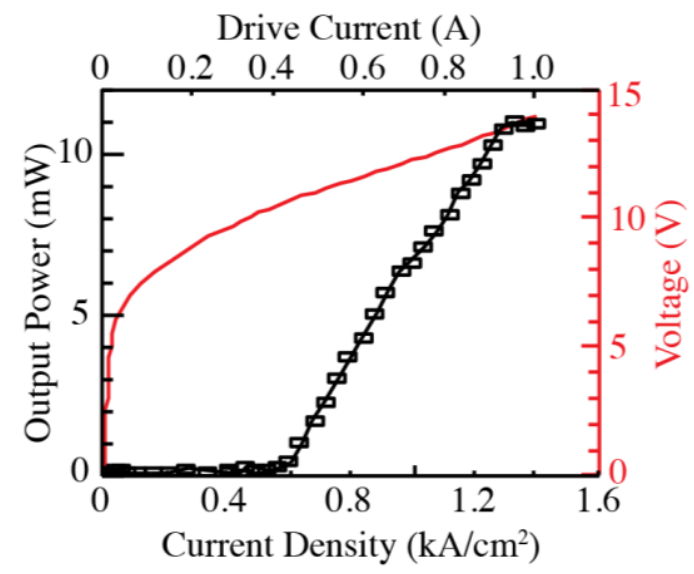

Figure 3. Pulsed output power and voltage $v$ s. injection current density and current at $20{ }^{\circ} \mathrm{C}$ of an integrated DFB QCL of Design D with III-V tapers on both sides. Light is collected from the polished passive SONOI facet.

All of the lasers were re-measured following removal of the tapers from the output sides. Figure 4 plots the light intensity vs. injection current density for all of the lasers studied (two with Design A, two with Design B, four with Design C, and two with Design D). In all cases, the threshold current densities increased only slightly (by $7 \%-26 \%$ ) while the differential efficiencies improved dramatically (by factors of 14-51). Furthermore, the devices that emitted too little light to measure when both tapers were intact became fully operational, with performance comparable to the others. Apart from one anomalous device (Design A), the slope efficiencies following removal of the tapers ranged from $161 \mathrm{~mW} / \mathrm{A}$ (for a laser with Design C) to $541 \mathrm{~mW} / \mathrm{A}$ (Design D). The maximum measured output power was $211 \mathrm{~mW}$ (not yet saturated), as seen in Figure 4d. The threshold current densities ranged from 0.71 to $1.36 \mathrm{kA} / \mathrm{cm}^{2}$ for Designs A, B, and D, while the thresholds for devices with Design C were somewhat higher $\left(1.44-1.83 \mathrm{kA} / \mathrm{cm}^{2}\right)$.

The observation of low threshold current densities, both before and after the tapers were polished off, indicates that the taper's primary effect was to limit the collection efficiency outside of the DFB cavity rather than to increase the loss within the primary laser cavity. The slight increase in threshold current after removal of the taper suggests that the reflectivity from the taper is higher than that of the polished (but uncoated) hybrid Si/III-V facet, whereas a large increase in the slope efficiency after the polishing indicates that the transmission through the taper is very low. This is consistent with the findings of our previous investigation of heterogeneously integrated QCLs, from which we concluded that the taper reflections are strong enough to form the primary Fabry-Pérot lasing cavity [17]. 
(a)

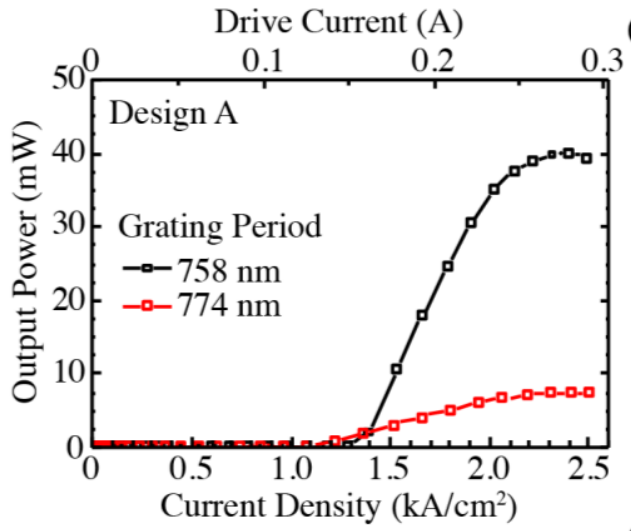

(c)

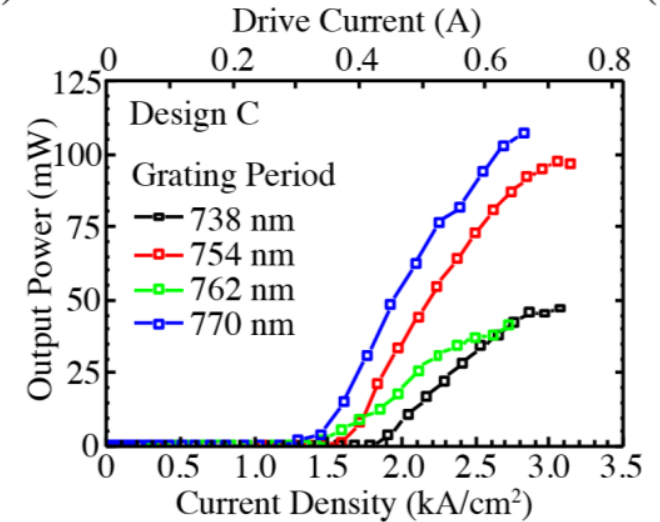

(b)

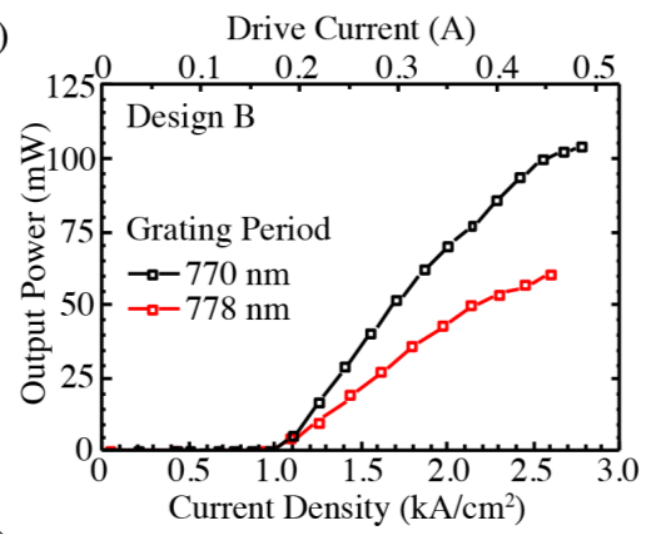

(d)

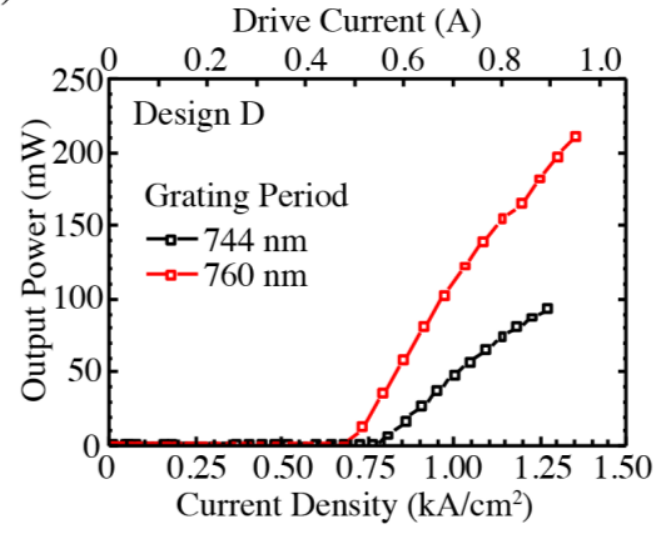

Figure 4. Pulsed output power vs. injection current density at $20{ }^{\circ} \mathrm{C}$ for DFB QCLs with the four different designs and various grating pitches. Light is collected from a polished hybrid $\mathrm{Si} / \mathrm{III}-\mathrm{V}$ facet.

The narrow III-V waveguide of Design A and the $\mathrm{TM}_{10}$ mode of Design C (see Figures 2 and 5 below) induce greater mode interaction with the InP mesa sidewalls relative to the other designs. The additional internal loss contributed by sidewall roughness most likely causes the higher current densities observed for the lasers of Design A and Design C. Although a laser with Design A displayed the second highest slope efficiency ( $489 \mathrm{~mW} / \mathrm{A})$, that result may be related more closely to out-coupling efficiency than to loss.

The solid lines in Figure 5 represent the slow-axis far-field profiles for one laser with each waveguide geometry. The single-lobe distributions observed for devices with Designs A, B, and $\mathrm{D}$ indicate lasing primarily in the fundamental $\mathrm{TM}_{00}$ mode. The two lobes seen in the profile for Design $C$ indicate that the higher-order $\mathrm{TM}_{10}$ mode dominates the emission, although the absence of a complete central null suggests that the fundamental mode also contributes. The dashed curves are FIMMWAVE simulations of the far-field distributions corresponding to the $\mathrm{TM}_{00}$ and $\mathrm{TM}_{10}$ modes of each waveguide design at the hybrid $\mathrm{Si} / \mathrm{III}-\mathrm{V}$ facets. These agree well with the measured profiles, with the exception of Design $C$ near zero degrees. The fast-axis profile measured for the device with Design B displays a similar symmetric single-lobe distribution.

These mode selections are generally consistent with the optical confinement distributions simulated for each of the active cross-section designs. The second-order $\mathrm{TM}_{10}$ mode is calculated to be above cutoff for the narrow $4 \mu \mathrm{m}$ mesa of Design A. While Design B supports a $\mathrm{TM}_{10}$ mode with high active region confinement, that mode resides almost entirely in the III-V mesa, overlaps significantly less with the Si surface grating, and interacts more with the mesa sidewalls. The 3.5- $\mu$ m-wide Si waveguide of Design $C$ is wide enough to contain much of the $\mathrm{TM}_{00}$ mode, which limits its active region confinement $(\Gamma=0.46)$ compared to the $\mathrm{TM}_{10}$ mode $(\Gamma=0.73)$. However, this configuration may allow both modes to lase simultaneously, given that the fundamental mode may suffer less from 
sidewall scattering loss. The apparent operation of the laser with Design D in a single mode is not as easily explained, since both the $\mathrm{TM}_{00}$ and $\mathrm{TM}_{10}$ modes have sufficient overlap with the active region and grating. One possibility is that the wider higher-order mode may have additional loss associated with optical leakage into the silicon slab on both sides of the 4 - $\mu$ m-wide air trenches that define the silicon waveguide.

(a)

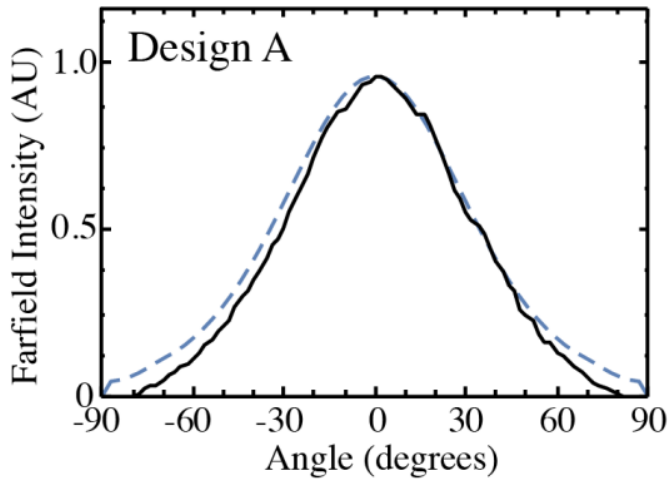

(c)

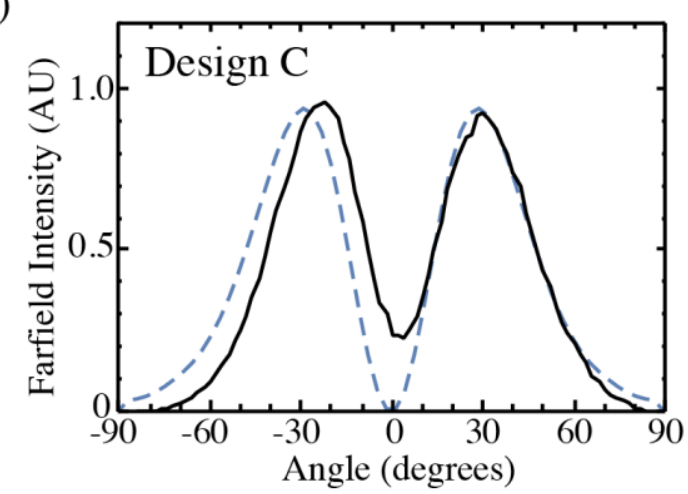

(b)

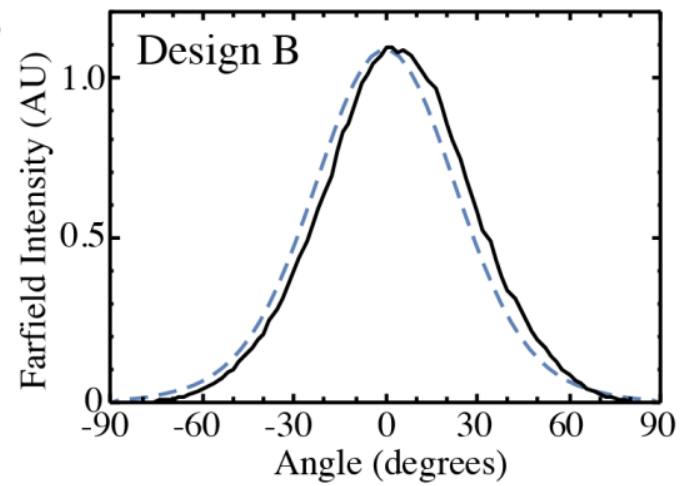

(d)

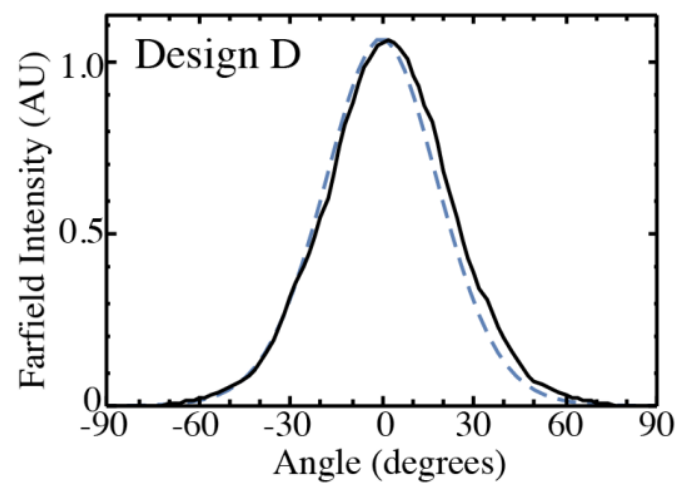

Figure 5. Slow-axis far field profiles for one laser of each active region design, at currents of 200, 350, 500, and $700 \mathrm{~mA}$ for Designs A-D, respectively. The solid curves show the measure profiles while the dashed curves show the simulated profiles for the $\mathrm{TM}_{00}$ mode in (a), (b), and (d) and the $\mathrm{TM}_{10}$ mode in (c).

Spectral measurements at $20{ }^{\circ} \mathrm{C}$ were acquired with a Digikrom $0.5 \mathrm{~m}$ monochromator with $1.5 \mathrm{~nm}$ resolution. Figure 6 shows the spectra for lasers of each geometry and various grating periods. In all cases, a primary lasing peak at a wavelength ranging from 4.62 to $4.86 \mu \mathrm{m}$ tracks the central Bragg frequency of the particular DFB grating, although many of the lasers emit in multiple modes. The weaker spectral features likely result from Fabry-Pérot resonances corresponding to reflections between the polished hybrid Si/III-V facet and the remaining III-V taper. Inconsistencies of these modes from device to device may be attributed to variations in the taper fabrication associated with non-uniform undercut at the taper tip across the chip after wet etching of the active region.

For the lasers with Designs A and D, the central mode of the $\lambda / 4$-shifted DFB grating appears split by the additional cavity resonance, while the lasers with Designs B and C show evidence for higher-order grating modes at the edges of the stop-band. For all four lasers with Design C, Figure 7a plots the wavelengths of the strongest peaks as a function of grating periodicity. The central peak (circled points) and two side modes follow a linear trend with the grating period, indicated by the dashed lines. This suggests a grating stopband width of $90 \mathrm{~nm}$ for this design. 
(a)

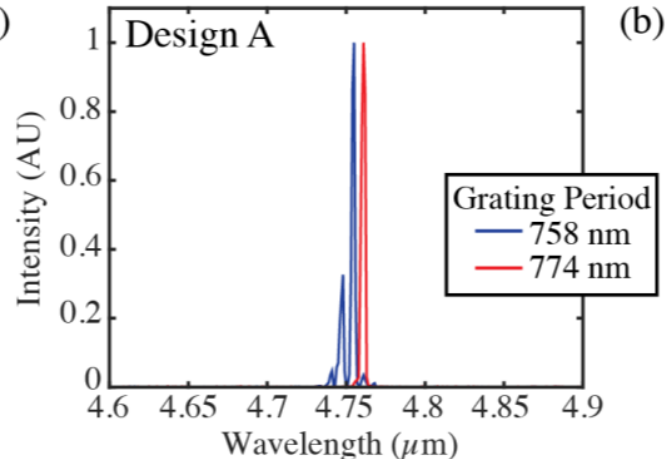

(c)

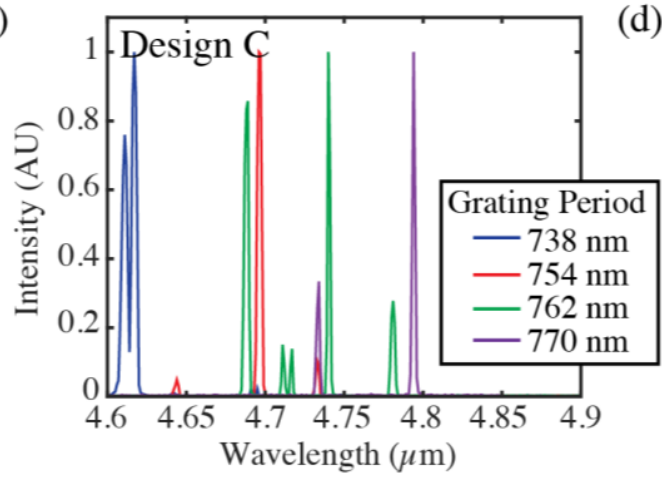

(b)
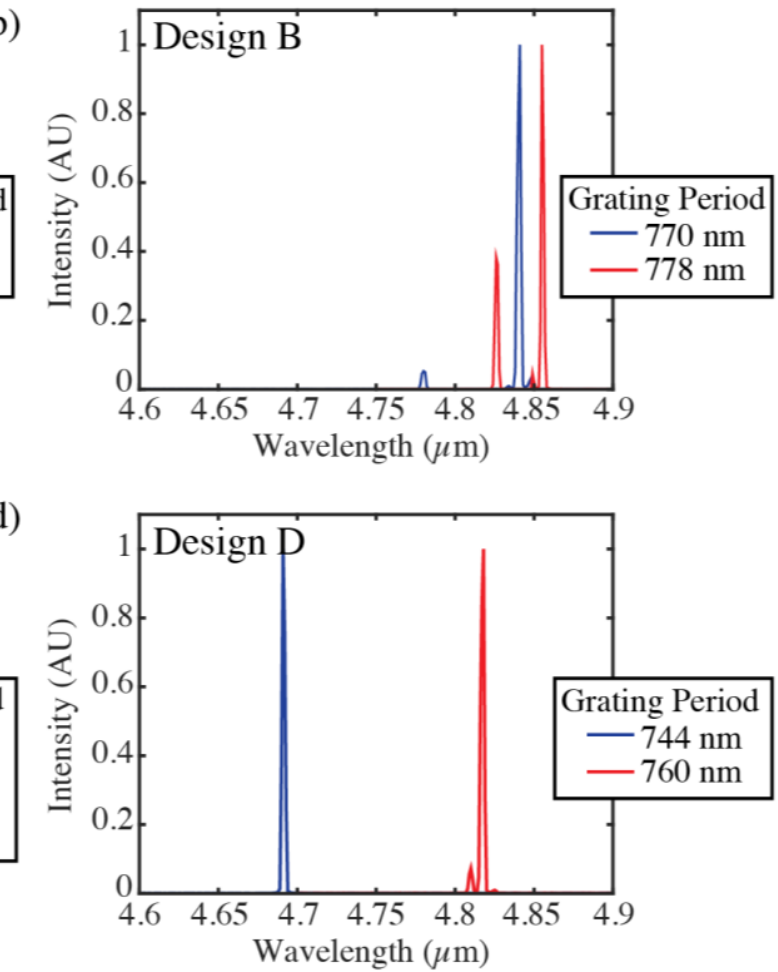

Figure 6. Normalized emission spectra at $20^{\circ} \mathrm{C}$ of DFBs with the four designs, as measured with a monochromator. The spectra were obtained at currents of $\approx 0.3 \mathrm{~A}$ for Designs A $(\mathbf{a})$ and B $(\mathbf{b}) ; 0.5 \mathrm{~A}$ for Design C (c); and 0.7 A for Design D (d). The legends show the DFB grating pitches of each device.

(a)

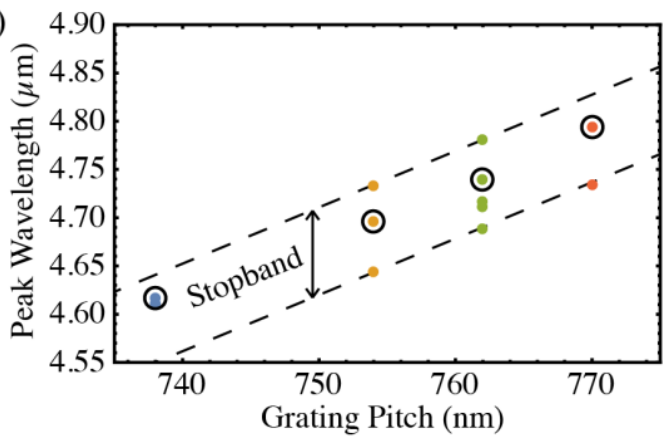

(b)

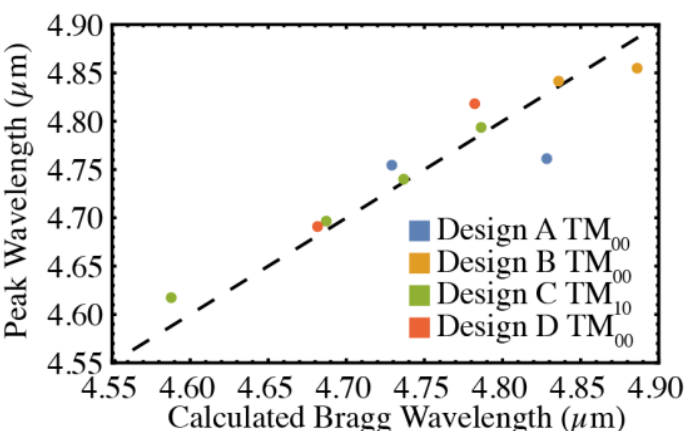

Figure 7. (a) Measured peak wavelengths as a function of DFB grating pitch for all four lasers of Design C, from the spectral data of Figure 6c. Multiple points of the same color (a single grating pitch) represent the multiple spectral peaks for that device. The circled points represent the strongest peak for that device. The dashed lines show that modes lasing at the edges of the 90-nm-wide stopband track the fabricated grating pitch; (b) Measured peak wavelength as a function of calculated Bragg wavelength for the strongest lasing mode of the devices shown in Figure 6.

Figure $7 \mathrm{~b}$ shows the wavelength of the strongest peak for each laser with all four designs $v s$. the estimated Bragg wavelength of the DFB grating. The first-order Bragg wavelength is calculated from the coupled mode theory approximation [26], $\lambda_{B}=2 \bar{n}_{e f f} \Lambda$, where $\Lambda$ is the pitch of the grating and $\bar{n}_{e f f}$ is the average effective index of the mode. The average effective index is approximated by an average of the effective indices of the optical mode simulated in FIMMWAVE (TM $\mathrm{TM}_{00}$ for Designs $\mathrm{A}, \mathrm{B}$, and $\mathrm{D}$, and $\mathrm{TM}_{10}$ for Design $\mathrm{C}$ ) with and without the $28 \mathrm{~nm}$ grating air gap, weighted by the measured duty cycle of the grating. The Bragg wavelength calculated directly from this value of 
$\bar{n}_{\text {eff }}$ is, on average, $1 \%$ lower than the measured peak wavelength. This inconsistency is most likely attributable to an overestimation of the effective index by the mode solver. Accordingly, the $\bar{n}_{\text {eff }}$ values used to calculate the Bragg Wavelength for Figure $7 \mathrm{~b}$ are adjusted by a factor of 0.99 . Note the nearly linear dependence of the experimental peak emission wavelength on the calculated Bragg wavelength. The only significant departure is for the same laser with Design A (emitting at $\approx 4.76 \mu \mathrm{m}$ ) that displayed anomalously low slope efficiency.

Figure 8a shows the light output $v s$. injection current for the laser of Design B with a grating period of $770 \mathrm{~nm}$, measured at a range of temperatures from 10 to $100{ }^{\circ} \mathrm{C}$. The threshold current density and differential slope efficiency $v$ s. temperature are shown in Figure 8b,c, respectively. The characteristic temperatures of $T_{0}=199 \mathrm{~K}$ for threshold and $T_{1}=222 \mathrm{~K}$ for efficiency are extracted from the exponential fits indicated by the lines.
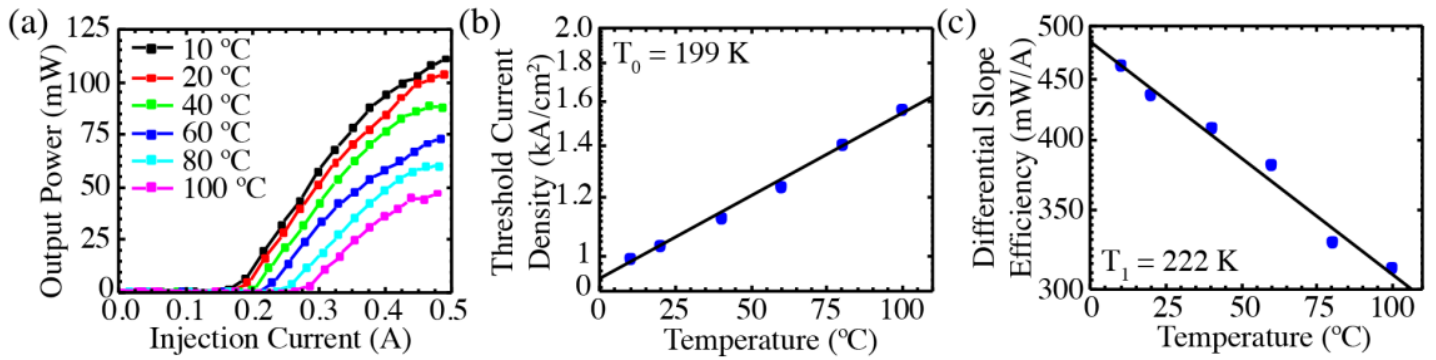

Figure 8. (a) Pulsed output power for a laser of Design B at temperatures ranging from $10{ }^{\circ} \mathrm{C}$ to $100{ }^{\circ} \mathrm{C}$; (b) Corresponding threshold current density $v s$. temperature, which yields a characteristic temperature of $T_{0}=199 \mathrm{~K}$; (c) Corresponding differential efficiency $v$ s. temperature, which yields a characteristic temperature of $T_{1}=222 \mathrm{~K}$.

Both of these relatively high pulsed characteristic temperatures are much higher than those observed for the Fabry-Pérot QCLs on silicon [17], which lased in pulsed mode only to $60^{\circ} \mathrm{C}$. One possibility is that the gain peak is better matched to the Bragg wavelength at higher temperatures. The much higher $T_{0}$ and $T_{1}$ values are consistent with both the significantly lower room temperature threshold current density compared to the Fabry-Pérot devices [17] and the relatively low injector sheet-doping density $\left(\sim 0.5 \times 10^{11} \mathrm{~cm}^{-2}\right)$ [27].

Figure 9 shows the emission spectra for the same device over the same range of temperatures. The single primary peak tunes at a rate of $0.25 \mathrm{~nm} / \mathrm{K}$, which is consistent with the expected shift of the modal index that governs the DFB mode rather than the shift of the gain peak.

(a)

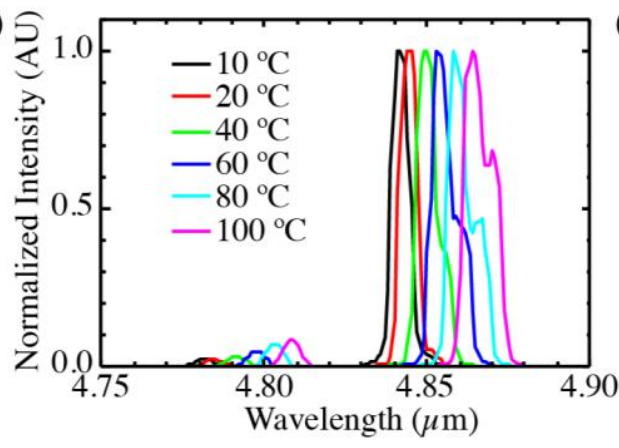

(b)

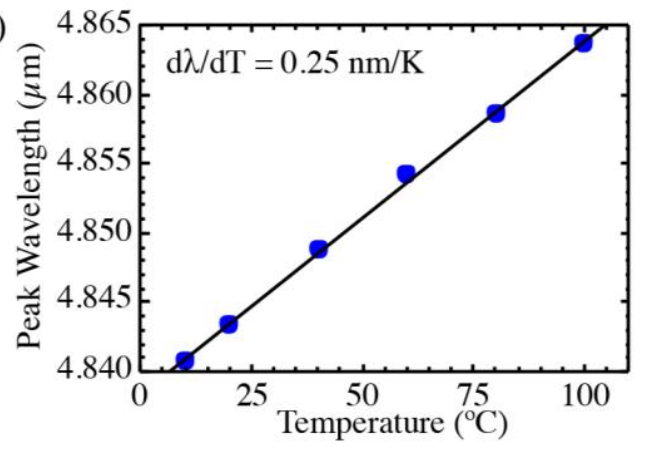

Figure 9. (a) Temperature-dependent emission spectra for the same laser of Design B whose temperature-dependent $L-I$ characteristics are shown in Figure 8; (b) Peak wavelength as a function of temperature. 
Given their low threshold current densities and high characteristic temperatures, $\mathrm{CW}$ operation of these lasers at room temperature should be achievable with improved heat dissipation.

\section{Conclusions}

We have demonstrated quantum cascade lasers heterogeneously integrated with SONOI waveguides that incorporate shallow $\lambda / 4$-shifted distributed feedback surface gratings etched into the silicon waveguides underneath the bonded III-V layers. Lasers with four different active region geometries were measured. Multiple grating periodicities systematically selected lasing modes at wavelengths ranging from 4.62 to $4.86 \mu \mathrm{m}$. The lasers operate up to $100{ }^{\circ} \mathrm{C}$, and emit over $200 \mathrm{~mW}$ of pulsed power with slope efficiencies up to $541 \mathrm{~mW} / \mathrm{A}$ from a hybrid Si/III-V polished facet. Threshold current densities $<1 \mathrm{kA} / \mathrm{cm}^{2}$ are observed for devices both before and after removal of the taper adjacent to the output facet. Although strong reflection from and low transmission through the III-V taper are observed, it should be possible to significantly improve the efficiency of mode transfer to the silicon waveguide by optimizing both the fabrication process and the waveguide design. These lasers are suitable for integration in a mid-infrared photonic integrated circuit.

Acknowledgments: This work was supported by the Office of Naval Research (ONR) (N00014-13-C-0147) and National Science Foundation (NSF) (DGE 1144085).

Author Contributions: J.E. Bowers and J.R. Meyer conceived the experiment and supervised the project. A. Spott designed the devices, fabrication process, and mask, and performed the facet polishing. J. Peters fabricated the devices. M.L. Davenport contributed to the fabrication process design. M.L. Davenport, E.J. Stanton, I. Vurgaftman, J.R. Meyer, and J.E. Bowers contributed to the laser design and data interpretation. C. Zhang contributed to the DFB grating design and processing. C.D. Merritt and W.W. Bewley performed the laser characterization experiments. C.S. Kim performed the post-fabrication processing, mounting, and wire-bonding. J. Kirch, L.J. Mawst, and D. Botez contributed to the III-V material design and performed the MOCVD growth of the QCL material. A. Spott wrote the paper.

Conflicts of Interest: The authors declare no conflicts of interest.

\section{References}

1. Rothman, L.S.; Gordon, I.E.; Babikov, Y.; Barbe, A.; Benner, D.C.; Bernath, P.F.; Birk, M.; Bizzocchi, L.; Boudon, V.; Brown, L.R.; et al. The HITRAN2012 molecular spectroscopic database. J. Quant. Spectrosc. Radiat. Transfer 2013, 130, 4-50. [CrossRef]

2. Estevez, M.C.; Alvarez, M.; Lechuga, L.M. Integrated optical devices for lab-on-a-chip biosensing applications. Laser Photonics Rev. 2012, 6, 463-487. [CrossRef]

3. Gålfalk, M.; Olofsson, G.; Crill, P.; Bastviken, D. Making methane visible. Nat. Clim. Chang 2015, 1-5. [CrossRef]

4. Pepe, F.; Ehrenreich, D.; Meyer, M.R. Instrumentation for the detection and characterization of exoplanets. Nature 2014, 513, 358-366. [CrossRef] [PubMed]

5. Spott, A.; Liu, Y.; Baehr-Jones, T.; Ilic, R.; Hochberg, M. Silicon waveguides and ring resonators at $5.5 \mu \mathrm{m}$. Appl. Phys. Lett. 2010, 97, 213501. [CrossRef]

6. Nedeljkovic, M.; Penadés, J.S.; Mitchell, C.J.; Khokhar, A.Z.; Stankovic, S.; Bucio, T.D.; Littlejohns, C.G.; Gardes, F.Y.; Mashanovich, G.Z. Surface-grating-coupled low-loss Ge-on-Si rib waveguides and multimode interferometers. IEEE Photon. Technol. Lett. 2015, 27, 1040-1043. [CrossRef]

7. Malik, A.; Muneeb, M.; Shimura, Y.; Van Campenhout, J.; Loo, R.; Roelkens, G. Germanium-on-silicon planar concave grating wavelength (de)multiplexers in the mid-infrared. Appl. Phys. Lett. 2013, 103, 161119. [CrossRef]

8. Khan, S.; Chiles, J.; Ma, J.; Fathpour, S. Silicon-on-nitride waveguides for mid- and near-infrared integrated photonics. Appl. Phys. Lett. 2013, 102, 121104. [CrossRef]

9. Malik, A.; Dwivedi, S.; van Landschoot, L.; Muneeb, M.; Shimura, Y.; Lepage, G.; van Campenhout, J.; Vanherle, W.; van Opstal, T.; Loo, R.; et al. Ge-on-Si and Ge-on-SOI thermo-optic phase shifters for the mid-infrared. Opt. Express 2014, 22, 28479-28488. [CrossRef] [PubMed] 
10. Wang, R.; Sprengel, S.; Muneeb, M.; Boehm, G.; Baets, R.; Amann, M.-C.; Roelkens, G. 2 m wavelength range InP-based type-II quantum well photodiodes heterogeneously integrated on silicon photonic integrated circuits. Opt. Express 2015, 23, 26834. [CrossRef] [PubMed]

11. Wang, R.; Muneeb, M.; Sprengel, S.; Boehm, G.; Malik, A.; Baets, R.; Amann, M.-C.; Roelkens, G. III-V-on-silicon 2- $\mu \mathrm{m}$-wavelength-range wavelength demultiplexers with heterogeneously integrated InP-based type-II photodetectors. Opt. Express 2016, 24, 8480-8490. [CrossRef] [PubMed]

12. Muneeb, M.; Vasiliev, A.; Ruocco, A.; Malik, A.; Chen, H.; Nedeljkovic, M.; Penades, J.S.; Cerutti, L.; Rodriguez, J.B.; Mashanovich, G.Z.; et al. III-V-on-silicon integrated micro-spectrometer for the $3 \mu \mathrm{m}$ wavelength range. Opt. Express 2016, 24, 9465-9472. [CrossRef] [PubMed]

13. Spott, A.; Davenport, M.L.; Peters, J.; Bovington, J.; Heck, M.J. R.; Stanton, E.J.; Vurgaftman, I.; Meyer, J.R.; Bowers, J. Heterogeneously integrated $2.0 \mu \mathrm{m} \mathrm{CW}$ hybrid silicon lasers at room temperature. Opt. Lett. 2015, 40, 1480-1483. [CrossRef] [PubMed]

14. Yao, Y.; Hoffman, A.J.; Gmachl, C.F. Mid-infrared quantum cascade lasers. Nat. Photon. 2012, 6, $432-439$. [CrossRef]

15. Vurgaftman, I.; Weih, R.; Kamp, M.; Meyer, J.R.; Canedy, C.L.; Kim, C.S.; Kim, M.; Bewley, W.W.; Merritt, C.D.; Abell, J.; et al. Interband cascade lasers. J. Phys. D Appl. Phys. 2015, 48, 123001. [CrossRef]

16. Kim, M.; Bewley, W.W.; Canedy, C.L.; Kim, C.S.; Merritt, C.D.; Abell, J.; Vurgaftman, I.; Meyer, J.R. High-power continuous-wave interband cascade lasers with 10 active stages. Opt. Express 2015, 23, 9664-9672. [CrossRef] [PubMed]

17. Spott, A.; Peters, J.; Davenport, M.L.; Stanton, E.J.; Merritt, C.D.; Bewley, W.W.; Vurgaftman, I.; Kim, C.S.; Meyer, J.R.; Kirch, J.; et al. Quantum cascade laser on silicon. Optica 2016, 3, 545-551. [CrossRef]

18. Komljenovic, T.; Srinivasan, S.; Norberg, E.; Davenport, M.L.; Fish, G.; Bowers, J.E. Widely tunable narrow-linewidth monolithically integrated external-cavity semiconductor lasers. IEEE J. Sel. Top. Quantum Electron. 2015, 21, 1501909. [CrossRef]

19. Werle, P.; Slemr, F.; Maurer, K.; Kormann, R.; Mücke, R.; Jänker, B. Near- and mid-infrared laser-optical sensors for gas analysis. Opt. Laser Eng. 2002, 37, 101-114. [CrossRef]

20. Bauer, C.; Sharma, A.K.; Willer, U.; Burgmeier, J.; Braunschweig, B.; Schade, W.; Blaser, S.; Hvozdara, L.; Müller, A.; Holl, G. Potentials and limits of mid-infrared laser spectroscopy for the detection of explosives. Appl. Phys. B 2008, 92, 327-333. [CrossRef]

21. Briggs, R.M.; Frez, C.; Borgentun, C.E.; Forouhar, S. Regrowth-free single-mode quantum cascade lasers with power consumption below 1 W. Appl. Phys. Lett. 2014, 105, 141117. [CrossRef]

22. Lu, Q.Y.; Bai, Y.; Bandyopadhyay, N.; Slivken, S.; Razeghi, M. 2.4 W room temperature continuous wave operation of distributed feedback quantum cascade lasers. Appl. Phys. Lett. 2011, 98, 181106. [CrossRef]

23. Wittmann, A.; Bonetti, Y.; Fischer, M.; Faist, J.; Blaser, S.; Gini, E. Distributed-feedback Quantum-Cascade Lasers AT $9 \mu \mathrm{m}$ Operating In Continuous Wave Up to 423 K. IEEE Photon. Technol. Lett. 2009, 21, 814-816. [CrossRef]

24. Zhang, C.; Srinivasan, S.; Tang, Y.; Heck, M.J.R.; Davenport, M.L.; Bowers, J.E. Low threshold and high speed short cavity distributed feedback hybrid silicon lasers. Opt. Express 2014, 22, 10202-10209. [CrossRef] [PubMed]

25. Evans, A.; Darvish, S.R.; Slivken, S.; Nguyen, J.; Bai, Y.; Razeghi, M. Buried heterostructure quantum cascade lasers with high continuous-wave wall plug efficiency. Appl. Phys. Lett. 2007, 91, 071101. [CrossRef]

26. Coldren, L.; Corzine, S.; Masonovic, M. Diode Lasers and Photonic Integrated Circuits, 2nd ed.; John Wiley \& Sons, Inc.: Hoboken, NJ, USA, 2012.

27. Botez, D.; Chang, C.-C.; Mawst, L.J. Temperature sensitivity of the electro-optical characteristics for mid-Infrared $(\lambda=3-16 \mu \mathrm{m})$-emitting quantum cascade lasers. J. Phys. D Appl. Phys. 2016, 49, 043001. [CrossRef]

(C) 2016 by the authors; licensee MDPI, Basel, Switzerland. This article is an open access article distributed under the terms and conditions of the Creative Commons Attribution (CC-BY) license (http://creativecommons.org/licenses/by/4.0/). 